\title{
Author Correction: Ultrafast bridge planarization in donor- $\pi$-acceptor copolymers drives intramolecular charge transfer
}

Palas Roy ${ }^{1}$, Ajay Jha (i) ${ }^{1}$, Vineeth B. Yasarapudi ${ }^{1}$, Thulasi Ram², Boregowda Puttaraju ${ }^{3}$, Satish Patil ${ }^{3}$

$\&$ Jyotishman Dasgupta ${ }^{1}$

Correction to: Nature Communications https://doi.org/10.1038/s41467-017-01928-z, published online 23 November 2017

The original version of this Article omitted the following from the Acknowledgements:

"Satish Patil thanks Department of Science and Technology, New Delhi, India for a Swarnajayanti fellowship."

This has now been corrected in both the PDF and HTML versions of the Article.

Published online: 03 January 2018

\begin{abstract}
(c) Open Access This article is licensed under a Creative Commons Attribution 4.0 International License, which permits use, sharing, adaptation, distribution and reproduction in any medium or format, as long as you give appropriate credit to the original author(s) and the source, provide a link to the Creative Commons license, and indicate if changes were made. The images or other third party material in this article are included in the article's Creative Commons license, unless indicated otherwise in a credit line to the material. If material is not included in the article's Creative Commons license and your intended use is not permitted by statutory regulation or exceeds the permitted use, you will need to obtain permission directly from the copyright holder. To view a copy of this license, visit http://creativecommons.org/licenses/by/4.0/.
\end{abstract}

(C) The Author(s) 2017

\footnotetext{
${ }^{1}$ Department of Chemical Sciences, Tata Institute of Fundamental Research, 400005 Mumbai, India. ${ }^{2}$ Department of Nuclear and Atomic Physics, Tata Institute of Fundamental Research, 400005 Mumbai, India. ${ }^{3}$ Solid State and Structural Chemistry Unit Indian Institute of Science, 560012 Bangalore, India Correspondence and requests for materials should be addressed to J.D. (email: dasgupta@tifr.res.in)
} 